CLINICAL STUDY

\title{
Differences in expression and activity of $11 \beta$-hydroxysteroid dehydrogenase type 1 and 2 in human placentas of term pregnancies according to birth weight and gender
}

\author{
V Mericq, P Medina, E Kakarieka ${ }^{1}$, L Márquez ${ }^{1}$, M C Johnson and G Iñiguez \\ Institute of Maternal and Child Research, Faculty of Medicine, University of Chile, Santa Rosa 1234, $2^{\circ}$ piso, Casilla 226-3, Santiago, Chile and \\ ${ }^{1}$ Hospital Clínico San Borja Arriarán, Santiago, Chile \\ (Correspondence should be addressed to G Iñiguez; Email: giniguez@med.uchile.cl)
}

\begin{abstract}
Background: Fetal exposure to maternal glucocorticoids may determine fetal growth and the programing of later disorders. Availability of the glucocorticoids in the placenta is regulated by the $11 \beta$-hydroxysteroid dehydrogenase (11 $\beta$-HSDs) enzymes. To date, there are discrepancies with regard to cortisol (F) cord blood levels in fetuses with intrauterine growth retardation in different species. Objective: To study the expression and activity of $11 \beta$-HSDs in placentas from full term small for gestational age (SGA), appropriate for gestational age (AGA) and large for gestational age (LGA) newborns, and cortisol cord blood concentration.

Methods: Twenty-five placentas from AGA, 24 SGA and 25 LGA were collected.

Results: SGA newborns had significantly lower and LGA newborns had significantly higher birth weight, birth length, head circumference, and placental weight than AGA counterparts. We observed a direct correlation between placental weight and birth weight, birth length and head circumference, and higher cord F levels in SGA newborns. The 11 $\beta$-HSD1 expression was similar among the SGA, AGA, and LGA placentas. However, within the placentas of SGA newborns, the $11 \beta$-HSD 1 mRNA levels were significantly reduced in the chorionic plate compared with basal plate. An inverse correlation between cord F levels and activity of 11 $\beta$-HSD1 in the chorionic plate of the SGA placentas

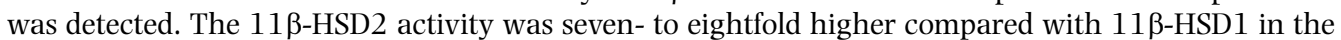
placentas, and there was a lower $11 \beta$-HSD2 activity in females' SGA placentas compared with the male SGA placentas.

Conclusion: We observed a lower expression and activity of 11ß-HSD1 in the chorionic plate of the SGA placentas, suggesting a possible compensatory mechanism to diminish the higher cortisol fetal concentrations observed in fetuses with intrauterine growth restriction.
\end{abstract}

European Journal of Endocrinology $161419-425$

\section{Introduction}

Intrauterine growth retardation (IUGR) is associated with an increased incidence of cardiovascular disease and alterations in glucose homeostasis in later life. Many hypotheses have been advanced to explain these features (1). Intrauterine alterations in adrenocortical function or cortisol (F) metabolism, which occur during gestation, may have long-lasting effects leading to these derangements in adulthood. Two different isoenzymes of 11ß-hydroxysteroid dehydrogenase type 1

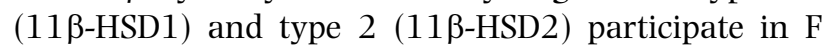
metabolism and both have been identified in human placentas $(2,3)$. The $11 \beta$-HSD1 is a bidirectional enzyme that acts primarily as an 11-oxoreductase forming active cortisol from inactive cortisone (4). Its activity in human placentas has been found to be lower than those of $11 \beta$-HSD2. Changes in these enzymes during gestation may be important in regulating fetal birth weight and in the mechanisms involved in human parturition $(5,6)$. Placental $11 \beta$-HSD2 mRNA levels have been reported to be significantly decreased in intrauterine growth restriction pregnancies when compared with gestationally matched, appropriately grown placentas (7). Decreased placental 11ß-HSD2 activity has been suggested to play a role in IUGR and to its metabolic consequences (8). Mutations in the $11 \beta$-HSD 2 gene invariably have reduced birth weight, and recently it has been shown that there is a reduced placental 11 1 -HSD2 activity in preterm pregnancies also present with IUGR (9). Interestingly, placental architecture and blood flow are not uniform across chorioallantoic human placental disk. Proximity to the umbilical cord, basal plate or chorionic plate may influence perfusion and protein and gene expression (10). Despite these limitations, it seems plausible that 
differences in sampling site contribute to variability in gene and protein expression across the placental disk (10). We hypothesize that the expression and/or the activity of $11 \beta$-HSDs differ between the chorionic and basal plates of the placentas according to the newborn birth weight in human term pregnancies. Because currently there is no information regarding the expression and placental activity of $11 \beta$-HSDs type 1 and 2 from newborns born small for gestational age (SGA) compared with those with macrosomia and whether there are differences according to gender in human term pregnancies, we designed a study to determine the mRNA expression and the activity of $11 \beta$-HSDs in full-term placentas from newborns born appropriate for gestational age (AGA), SGA, and large for gestational age (LGA) as well as to assess $\mathrm{F}$ concentrations in cord blood.

\section{Material and methods}

\section{Sample collection}

The placental tissue was collected immediately after delivery. We selected pregnancies from full-term pregnancies (37-40 week of gestation) defined by standard clinical criteria and with a birth weight between the 10th and the 90th centiles for gestational age defined as AGA; below the 10th centile was defined as SGA and over the 90th centile as LGA using the Chilean birth weight reference (11). Exclusion criteria were maternal hypertension, diabetes, use of glucocorticoids during pregnancy, or a reduced amount of amniotic fluid at term. All mothers gave their informed consent and this protocol was approved by the Institutional Review Board of the San Borja Arriarán Clinical Hospital in Santiago, Chile.

Each placenta was inspected by a pathologist (EK) for any visible abnormalities and was excluded in the presence of macroscopic alterations. Placental samples were rapidly processed as described by Wyatt et al. (10). Briefly, each placenta was sectioned transversally $(\sim 5 \mathrm{~cm})$ using a sterile scalpel near the cord insertion site. The tissue was subsequently divided into three horizontal segments from the basal towards the chorionic surface. Each sample was rinsed thoroughly in cold sterile saline solution $(\mathrm{NaCl} 9.0 \mathrm{~g} / \mathrm{l})$, and samples from the different sections were frozen in liquid nitrogen and stored at $-80{ }^{\circ} \mathrm{C}$ for RNA and protein analysis.

The cord blood was processed by the laboratory within $20 \mathrm{~min}$, centrifuged $\left(2000 \mathrm{~g}\right.$ for $10 \mathrm{~min}$ at $\left.4^{\circ} \mathrm{C}\right)$, and the sera were aliquoted and stored at $-20{ }^{\circ} \mathrm{C}$ until assayed.

\section{RNA purification, RT, and semi-quantitative PCR}

Total RNA was isolated from the frozen placentas (chorionic and basal plate samples) as described previously (12) using TRIzol Reagent (Invitrogen).
cDNA was synthesized from $2 \mu \mathrm{g}$ of total RNA, previously digested by DNase I (Fermentas AB, Vilnius, Lithuania), using random primers (Invitrogen) and $200 \mathrm{U}$ RevertAid H Minus M-MuLV reverse transcriptase (Fermentas) following the manufacturer's instructions.

The gene amplifications were assessed using specific pairs of primers: 11 $\beta$-HSD1 upstream, 5'-AGGAAAGCTCATGGGAGGACTAG-3' and downstream, 5'-ATGGTGAATATCATCATGAAAAAGATTC-3'; $11 \beta$-HSD 2 upstream, 5'-TCAAGACAGAGTCAGTGAGAAACG-3' and downstream, 5'-GGAACTGCCCATGAAGTG-3'; 18s rRNA upstream, 5'-GTAACCCGTTGAACCCATT-3' and downstream, 5'-CCATCCAATCGGTAGTAGCG-3'.

Two $\mu$ l of cDNA were added to the reaction mix (total volume of $25 \mu \mathrm{l}$ ) containing PCR buffer, $1.5 \mathrm{mmol} / \mathrm{l}$ $\mathrm{MgCl}_{2}, 0.625 \mathrm{U}$ Taq DNA polymerase (Invitrogen), $0.25 \mathrm{mmol} / \mathrm{l}$ nucleotide mix (Fermentas), and $0.4 \mu \mathrm{mol} / \mathrm{l}$ of each specific human primer (Integrated DNA Technologies, Miami, FL, USA). The PCR was performed in a $\mathrm{P} \times 2$ Thermal Cycler (Thermo Electron Corporation, Waltham, MA, USA) at $94{ }^{\circ} \mathrm{C}$ for $45 \mathrm{~s}$ (denaturation), $55^{\circ} \mathrm{C}$ for $60 \mathrm{~s}$ (annealing), and $72{ }^{\circ} \mathrm{C}$ for $90 \mathrm{~s}$ (extension), and repeated for 30 cycles. As an internal control, 18S rRNA was amplified in each sample following the same conditions described above, and repeated for 18 cycles. To determine that the amplification of all the genes was within a linear range, we evaluated the linearity of amplification of the corresponding transcripts in human placenta and we subsequently selected the number of cycles.

Amplified fragment products were visualized on a $1.0 \%$ agarose gel using ethidium bromide staining. Semi-quantification of PCR products was performed by image analysis (Kodak EDAS 290 Electrophoresis Documentation and Analysis System, Kodak 1D Image Analysis Software).

\section{Protein extraction}

The frozen placental tissue was powdered in a ceramic mortar with liquid $\mathrm{N}_{2}$ and homogenized for $30 \mathrm{~s}$ with a mechanical homogenizer (Kontes Glass Company, Vineland, NJ, USA) in ice-cold $0.1 \mathrm{M}$ PBS pH 7.5 supplemented with anti-proteases (Complete, Mini, EDTA-free Protease Inhibitor Cocktail Tablets, Roche Applied Science). The tissue homogenate was centrifuged at $10000 \mathrm{~g}$ for $30 \mathrm{~min}$ at $4{ }^{\circ} \mathrm{C}$. The resulting supernatant was collected and assayed for protein concentration using the BCA protein assay kit (Pierce, Rockford, IL, USA) with BSA as a standard.

\section{1 $\beta$-HSD activity studies: type 1 and type 2 isoforms}

Tissue homogenates were centrifuged for $10 \mathrm{~min}$ at $1000 \boldsymbol{g}$ to sediment large tissue fragments, and a protein assay was performed on the supernatant (BCA, Pierce). 
To measure the activities of $11 \beta-H S D 1$ and $11 \beta-$ HSD2, placental homogenates from chorionic and basal plates $(0.40 \mathrm{mg}$ of total protein) were incubated in $1.0 \mathrm{ml}$ phosphate buffer $(0.1 \mathrm{~mol} / \mathrm{l}$; $\mathrm{pH} 7.6)$ in the presence of 50000 c.p.m. of ${ }^{3} \mathrm{H}$ cortisone or ${ }^{3} \mathrm{H} \mathrm{F}$ (Amersham International), $0.1 \mu \mathrm{M}$ cortisone or $0.25 \mu \mathrm{M} \mathrm{F}$, and $400 \mathrm{nmol} / \mathrm{l}$ NADP or NAD respectively, for $30 \mathrm{~min}$ at $37^{\circ} \mathrm{C}$ in a shaking water bath. Aliquots were extracted into 10 volumes of dichloromethane, and steroids were separated by high-performance thin layer chromatography (HPTLC, Merck), using methanol-chloroform (5:95) as a mobile phase. The bands containing the labeled $\mathrm{F}$ and cortisone were identified by u.v. light of the cold carriers, cut out into scintillation vials, and measured in scintillation counter (Tracor Analytic Delta 300). The rates of $\mathrm{F}$ to cortisone or cortisone to $\mathrm{F}$ conversion were calculated from the specific activity of the labeled $\mathrm{F}$ or cortisone and the radioactivity of cortisone or $\mathrm{F}$, and results expressed as the amount of $\mathrm{F}$ or cortisone (picograms) formed per min per mg protein.

\section{Cortisol assay}

Cord blood cortisol was determined using a commercial RIA (Diagnostic Products Co., DPC, Los Angeles, CA, USA). The sensitivity of this assay is $1 \mu \mathrm{g} / \mathrm{dl}$. The intraand inter-assay coefficient of variations are 3.1 and $5.2 \%$ respectively.

\section{Statistical analyses}

Results are shown as mean \pm s.E.M. Differences within each group (SGA, AGA, and LGA) were assessed by oneway ANOVA or Kruskal-Wallis, followed by Bonferroni test for multiple comparisons. To compare the results of the basal and chorionic plates in each placenta, we used the paired $t$-test or Wilcoxon test. The studies of correlations were performed using the Pearson or Spearman test. Statistics were performed using SPSS version 11.5; a value of $P<0.05$ was considered significant.

\section{Results}

Twenty-four placentas from SGA newborns (14 males), 25 from LGA newborns (14 males), and 25 from AGA newborns (14 males) were collected. Of the total deliveries, $24.7 \%$ were by cesarean section. The median Apgar score after 1 and $5 \mathrm{~min}$ was nine. The anthropometrics and clinical data of all neonates are shown in Table 1. As expected, the SGA newborns had significantly lower birth weight SDS $(P<0.001)$, birth length SDS $(P<0.001)$, head circumference SDS $(P<0.001)$, and placental weight $(P<0.01)$ than the AGA and LGA newborns. Likewise, the LGA newborns
Table 1 Anthropometric characteristics of the small for gestational age (SGA), appropriate for gestational age (AGA), and large for gestational age (LGA) newborns.

\begin{tabular}{lccc}
\hline & SGA (24) & AGA (25) & LGA (25) \\
\hline $\begin{array}{l}\text { Gestational age } \\
\quad \text { (weeks) }\end{array}$ & $38.1 \pm 0.3$ & $39.2 \pm 0.2$ & $39.5 \pm 0.2$ \\
$\begin{array}{l}\text { Birth weight (SDS) } \\
\text { Birth length (SDS) }\end{array}$ & $-1.71 \pm 0.10^{*}$ & $0.25 \pm 0.13$ & $2.50 \pm 0.14^{\dagger}$ \\
$\begin{array}{l}\text { Head circumference } \\
\quad \text { (SDS) }\end{array}$ & $-0.10 \pm 0.25^{\star}$ & $0.65 \pm 0.20$ & $1.53 \pm 0.15^{\dagger}$ \\
Placental weight (g) & $4901 \pm 0.03$ & $0.15 \pm 0.04^{\dagger}$ \\
\hline
\end{tabular}

Data are shown as mean \pm S.E.M. ${ }^{*} P<0.05$ SGA versus AGA and LGA; ${ }^{\dagger} P<0.05$ LGA versus AGA.

had significantly higher birth weight SDS, birth length SDS, head circumference SDS, and placental weight than the AGA newborns. In addition, the cortisol cord blood levels were significantly higher in the SGA group (mean: 16.0, range: $8.6-31.2 \mu \mathrm{g} / \mathrm{dl}$ ) compared with the AGA (mean: 11.0, range: $4.7-15.4 \mu \mathrm{g} / \mathrm{dl}$ ) and LGA (mean: 10.3, range 5.1-17.3 $\mu \mathrm{g} / \mathrm{dl}$ ) newborns (Fig. 1).

\section{1 $\beta$-HSD1 and 11 $\beta$-HSD2 expression in the placenta}

The 11 $\beta$-HSD1 mRNA expression was similar among the SGA, AGA, and LGA placentas in both the chorionic and basal plates (Fig. 2A). However, within the placentas of SGA newborns, the $11 \beta$-HSD1 mRNA levels were significantly reduced $(P=0.013)$ in the chorionic plate compared with the basal plate of these placentas (Fig. 2B). The 11ß-HSD2 expression was similar in all the placentas, independently of the birth weight or sampling site (Fig. 2C).

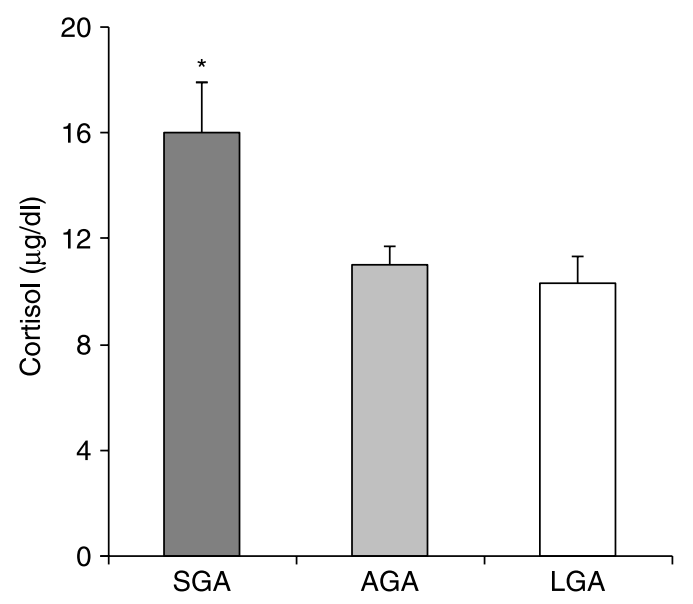

Figure 1 Cortisol cord blood levels in SGA, AGA, and LGA newborns. The concentrations are expressed as mean \pm s.E.M. Data were analyzed by two-way ANOVA followed by a post hoc LSD test. ${ }^{*} P<0.05$; SGA versus $A G A$ and LGA newborns. 

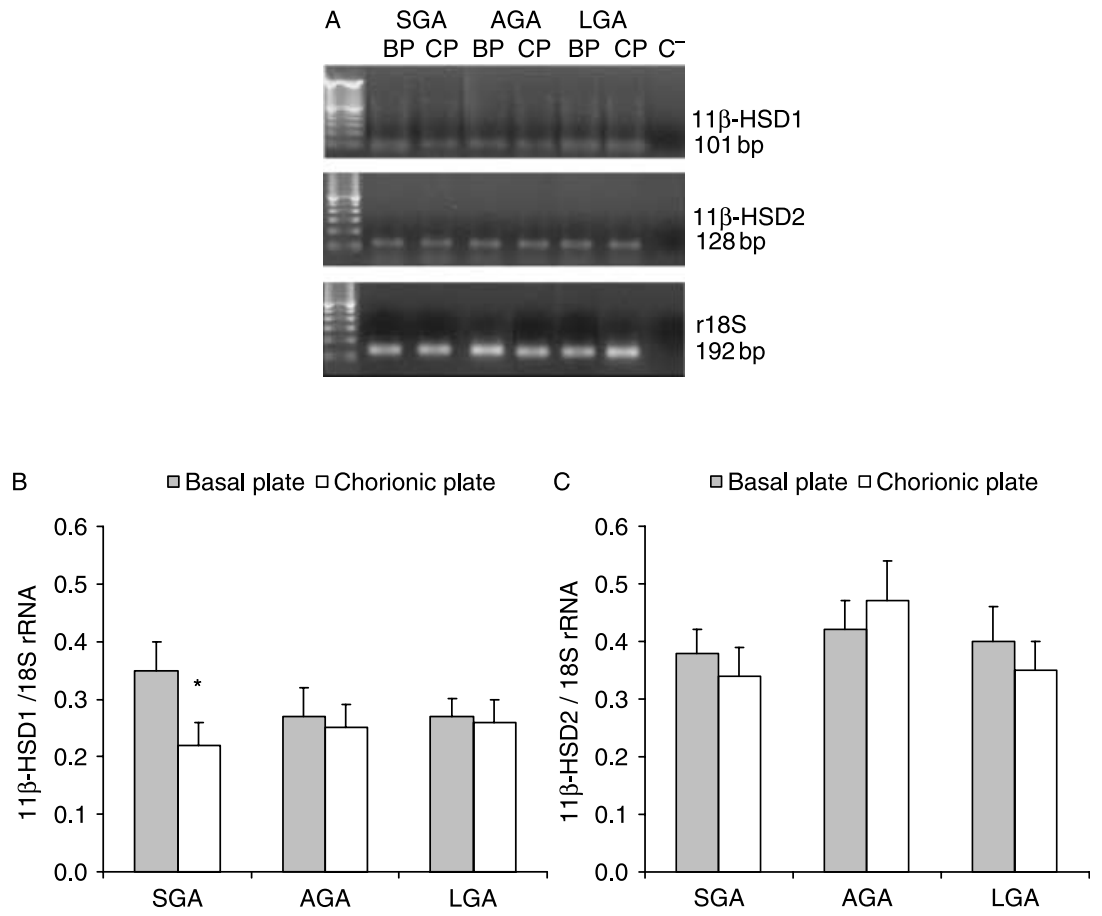

\begin{abstract}
Figure 2 Semi-quantitative RT-PCR was used to evaluate $11 \beta-H S D 1$ mRNA expression. The gene for ribosomal $18 \mathrm{~S}$ subunit ( $\mathrm{r} 18 \mathrm{~S})$ was used as an internal control (A, representative gel). Evaluation of the expression of $11 \beta-H S D 1(B)$ and $11 \beta$-HSD2 (C) in the basal (BP) and chorionic plates $(C P)$ of the placentas from SGA $(n=24)$, AGA $(n=25)$, and LGA $(n=25)$ newborns. The values represent the mean \pm s.E.M. of two different RT-PCRs, ( $\mathrm{C}^{-}$, negative control). ${ }^{*} P<0.05 \mathrm{CP}$ versus BP (Wilcoxon test).
\end{abstract}

\section{$11 \beta$-HSD1 and $11 \beta$-HSD2 activities in the placenta}

We observed a lower activity of $11 \beta$-HSD 1 in both chorionic and basal plates of the SGA placentas, compared with the activity observed in the AGA and LGA placentas. This activity was significantly lower in the chorionic plate of the SGA placentas compared with the chorionic plate of the AGA placentas $(0.89 \pm 0.03$ vs $1.32 \pm 0.14 \mathrm{pg} / \mathrm{min}$ per $\mathrm{mg}$ protein, $P=0.020$ ). The activity of the 11ß-HSD2 enzyme in placenta was seven- to eightfold higher compared with the activity of $11 \beta$-HSD1, $(P<0.01)$ and there were no differences among the three groups of newborn weight placentas.

The $11 \beta$-HSD1 and 11 $\beta$-HSD2 activities were studied according to the newborn gender. There were no differences of enzyme activities between females $(n=32)$ and males $(n=42)$ in the whole group of placentas. However, when placentas were separated according to the newborns' birth weight, we observed a lower activity of the $11 \beta$-HSD1 (Fig. 3A) in the chorionic plate of female SGA placentas compared with the chorionic plate of the female AGA placentas $(0.89 \pm 0.03$ vs $1.32 \pm 0.14 \mathrm{pg} / \mathrm{min}$ per $\mathrm{mg}$ protein, $P=0.029$ ), as well as in male SGA placentas compared with the chorionic plate of the male AGA placentas $(0.94 \pm 0.07$ vs $1.31 \pm 0.20 \mathrm{pg} / \mathrm{min}$ per $\mathrm{mg}$ protein, $P=0.037)$. However, within the AGA placentas, we observed differences in the $11 \beta$-HSD2 activity according to the newborn gender. In the females' AGA placentas $(n=11)$, a lower activity for $11 \beta$-HSD2 (Fig. 3B) was detected compared with the male AGA placentas $(n=14)$ in the chorionic plate $(5.2 \pm 0.9$ vs 9.5 $\pm 1.0 \mathrm{pg} / \mathrm{min}$ per $\mathrm{mg}$ protein, $P=0.007)$ as well as in the basal plate $(7.6 \pm 1.0 \mathrm{vs} 9.5 \pm 1.0 \mathrm{pg} / \mathrm{min}$ per $\mathrm{mg}$ protein, $P=0.091$ ). These differences in $11 \beta$-HSD2 activity were not observed in SGA or LGA placentas.

\section{Correlation studies}

We found a direct correlation between the weight of the placenta with birth weight SDS $(r=0.749, P<0.001)$, birth length SDS $(r=0.647, P<0.001)$, and birth head circumference SDS $(r=0.693, P<0.001)$ for the whole group. A direct correlation was found between placental weight with $11 \beta$-HSD1 activity in the chorionic plate $(r=0.359, P=0.006)$ for the whole group. Conversely, there was no significant correlation between placental weight and $11 \beta$-HSD1 or $11 \beta$-HSD2 expression (data not shown). Cord blood levels of cortisol in the whole group correlated inversely with birth weight $(r=-0.369, P=0.005)$, placental weight $(r=-0.426$, $P=0.001)$, and with $11 \beta$-HSD1 activity in the chorionic plate $(r=-0.315, P=0.015)$.

\section{Discussion}

In the present study, we analyzed the expression and activity of 11- $\beta$ HSD type 1 and 2 in human placentas of term pregnancies according to birth weight and gender. We observed a direct correlation between placental 

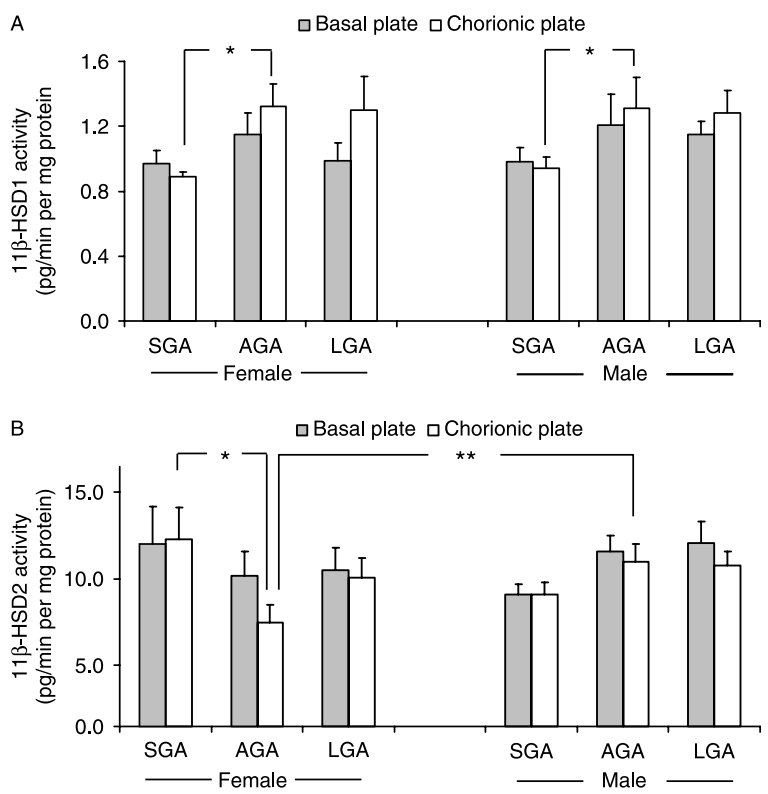

Figure 3 11 $\beta$-HSD1 (A) and 11 $\beta$-HSD2 (B) enzymatic activity according to the newborn gender in the basal (BP) and chorionic plates $(C P)$ of the placentas from SGA (male $=14$ and female $=10)$, AGA (male $=14$ and female $=11)$, and LGA $($ male $=14$ and female $=11)$. The values represent the mean \pm S.E.M. of two different activity determinations. ${ }^{*} P<0.05$ SGA CP versus AGA CP and ${ }^{* *} P<0.05$ female AGA versus male AGA in the CP of the placentas.

weight and birth weight SDS, birth length SDS and head circumference SDS. In addition, we found higher cord F levels in SGA at term newborns. However, in this regard, there are some discordant observations $(13,14)$. No differences in $\mathrm{F}$ from mixed umbilical cord serum in SGA newborns compared with matched AGA controls have been detected (14). Of note, in this later report, ten subjects were born preterm and three postterm, and since gestational age influences adrenal function, this result might be biased. In addition, recently Strinic et al., including only term newborns have found lower F levels in IUGR fetuses in umbilical venous blood (13). The latter observation has been also reported in animals (15). In mammals, glucocorticoids are essential for normal fetal organ growth and maturation (16). However, excessive exposure to glucocorticoids in utero leads to IUGR $(16,17)$, giving support to our results of increased $\mathrm{F}$ cord blood levels in SGA newborns. It has been suggested that the rise in plasma $\mathrm{F}$ concentrations in SGA fetuses (18) is a mechanism to combat hypoglycemia and may contribute to the maturation of fetal tissues. However, in human fetuses, there is no plasma $\mathrm{F}$ surge before 36 week's gestation by which time most fetal organs are mature (19).

The cause of increased blood $\mathrm{F}$ in fetuses with suspected IUGR is debatable. Fetal plasma ACTH has been reported to be decreased, which might be due to the negative feedback from increased fetal $\mathrm{F}$ concentrations or the direct consequence of reduced placental size and possibly reduced placental production of ACTH, corticotrophin-releasing hormone (CRH), or both (20) Therefore, one likely explanation is increased adrenal blood flow and adrenal hyperplasia, the consequence of redistribution in fetal circulation in response to hypoxemia. Increased plasma $\mathrm{CRH}-\mathrm{ACTH}$ in the umbilical cord of 28 growth-retarded fetuses has been reported, strongly suggesting that placental CRH may be stimulated in conditions of chronic stress, and in turn modulates fetal pituitary-adrenal function in high risk pregnancies (21).

The 11 $\beta$-HSD1 expression was similar among the SGA, AGA, and LGA placentas in both the chorionic and basal plates of the placentas. However, only within the placentas of SGA newborns, the $11 \beta$-HSD1 mRNA levels were significantly reduced in the chorionic plate compared with the basal plate of these placentas. Interestingly, we observed an inverse correlation between cord $\mathrm{F}$ levels with activity of $11 \beta$-HSD1 in the chorionic plate of the SGA placentas. In addition, the $11 \beta$-HSD1 activity in the SGA placentas was lower compared with the enzyme activity observed in the AGA and LGA placentas, and this difference was strengthened when comparing the chorionic plate of SGA placentas with the chorionic plate of AGA placentas and in placentas from female newborns. These findings have not been reported previously. In human pregnancies with IUGR, a decreased expression of $11 \beta$-HSD in placenta has been reported (22). Nevertheless, this finding must be interpreted with caution since it included term and preterm neonates. In fetal sheep, a specific increase in the expression of $11 \beta$-HSD1 mRNA in the liver of growth-restricted fetuses in late gestation has been observed (23). The authors suggest that an increased hepatic exposure to $\mathrm{F}$ in the growth-restricted fetus may be important in the reprograming of hepatic physiology that occurs after growth restriction. This possible regulation of the $11 \beta$-HSD1 enzymes in the placenta by $\mathrm{F}$ is also supported by the direct correlation between the placental weight and activity to 11ß-HSD1 in the chorionic side of the placentas and an inverse correlation with cord blood F. These findings point towards a compensatory mechanism of the fetal side of the placental to higher levels of fetal F. Several in vivo and $e x$ vivo studies have shown that the $\mathrm{GH}$-insulin-like growth factor 1 (IGF1) system inhibits the expression and activity of $11 \beta$-HSD1 resulting in reduced local regeneration of $\mathrm{F}$. Recently, the mechanism through which GH inhibits the 11 $\beta$-HSD1 gene promoter activity has been shown to be via IGF1 in HepG2 cells (24). Interestingly, in the chorionic plate of the SGA placentas, we have found an increased expression of IGF1, and thus this could be a mechanism through which the $11 \beta$-HSD1 gene is decreased in the chorionic plate of the SGA placentas (25).

As has been previously reported, the $11 \beta$-HSD2 enzyme activity was seven- to eightfold higher compared with $11 \beta$-HSD1 activity from the three 
groups of placentas. Decreased placental 11ß-HSD2 activity has been suggested as a reason for IUGR and its metabolic consequences. In the present study, there were no significant differences in the mRNA expression and activity of $11 \beta-H S D 2$ among the three groups of placentas from newborns with different birth weights. Moreover, no differences in the $11 \beta-H S D 2$ mRNA expression and protein activities from the chorionic plate compared with the basal plate were observed among the SGA, AGA, and LGA placentas. Our findings are in contrast to other recent reports. In one study in 19 IUGR placentas of different gestational ages, a decreased 11 $\beta$-HSD2 gene expression was observed in intrauterine growth restriction pregnancies compared with placentas from gestational matched AGA newborn (7). Importantly, the numbers of term placentas with IUGR in this study were only four and with very severe documented IUGR, not only a low birth weight newborn. In small preterm infants, reduced placental $11 \beta$-HSD2 activity is associated with low relative birth weight (24) and severe fetal distress (9). It is important to point out that in the latter study, the placentas included were from pregnancies between 22 and 32 weeks of gestational age and the $11 \beta$-HSD2 enzyme expression increases after 28 weeks by 12 -fold. Deficiency of the barrier to maternal glucocorticoids may represent a common pathway between the maternal environment and feto-placental programing of later disease. However, we did not find significant variations in the expression or in the activity of this enzyme among the different groups. This finding is in agreement with Rogerson et al. (26) who reported that the enzymatic activity and mRNA levels of $11 \beta-H S D 2$ measured in 111 human placentas taken from normal births were not correlated with either fetal or placental weight. These studies suggest that variations in placental $11 \beta$-HSD type 2 activities do not influence fetal or placental weight in humans. The expression and activity of this enzyme in fresh frozen human placenta increase progressively from first and second to third trimester (term) pregnancies at a time when maternal circulating levels of glucocorticoid are rising. The finding of attenuated placental 11 $\beta$-HSD2 activity in IUGR in some reports, but not others, must be carefully interpreted due to the differences in expression and activity in this enzyme throughout gestation (24). One of the strengths of our report is that gestational ages were within a narrow range of term pregnancies. On the other hand, severe IUGR is usually interrupted earlier than term and thus may have precluded us to find significant differences of expression and activity of this enzyme in term placentas (27). The capacity of $11 \beta$-HSD2 is massive, allowing maintenance of fetal $\mathrm{F}$ concentrations several times lower than maternal $\mathrm{F}$, and, at least in term infants, three-fourths of $\mathrm{F}$ concentrations originate from the fetal adrenals (28).

Nevertheless, we observed a lower 11 $\beta$-HSD2 activity in AGA female placentas compared with AGA male placentas. These gender differences were not found in the other birth weight groups of placentas, and yet we do not have a plausible explanation about the meaning of this observation. In a previous study by Murphy et al. (29), the authors document a different effect by fetus gender in asthmatic pregnant women in placental $11 \beta$-HSD2 activity, but not within the placentas collected from mothers without asthma. The differences with our findings might be due to tissue extracted from total placenta and the rather small sample size. We hypothesize that the lower activity of $11 \beta-H S D 2$ in AGA females might be a consequence of differences in estrogen levels (30).

In summary, we observed in full-term pregnancies, a

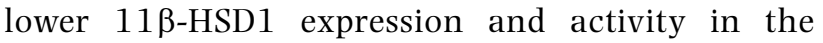
chorionic plate of the SGA placentas, suggesting a possible compensatory mechanism to diminish the higher $\mathrm{F}$ fetal concentrations observed in fetuses with intrauterine growth restriction. The finding of different expression and/or the activity of $11 \beta$-HSDs between the chorionic and basal plate of the placentas according to the newborn birth weight and according to gender have not been reported previously and point towards a possible different regulation of this enzyme within the placenta.

\section{Declaration of interest}

There is no conflict of interest that could be perceived as prejudicing the impartiality of the research.

\section{Funding}

This work was supported by the Fondo Nacional de Ciencia y Tecnología de Chile (FONDECYT N ${ }^{\circ} 106$ 1082).

\section{Acknowledgements}

We are very grateful to Dr Saul Malozowski for his thoughtful comments.

\section{References}

1 Phillips DI. Programming of the stress response: a fundamental mechanism underlying the long-term effects of the fetal environment? Journal of Internal Medicine 2007261 453-456.

2 Stewart PM, Rogerson FM \& Mason JI. Type 2 11ß-hydroxysteroid dehydrogenase messenger ribonucleic acid and activity in human placenta and fetal membranes: its relationship to birth weight and putative role in fetal adrenal steroidogenesis. Journal of Clinical Endocrinology and Metabolism 199580 885-890.

3 Sun K, Yang K \& Challis JR. Differential expression of $11 \beta$-hydroxysteroid dehydrogenase types 1 and 2 in human placenta and fetal membranes. Journal of Clinical Endocrinology and Metabolism 199782 300-305.

4 Bujalska IJ. Walker EA, Hewison M \& Stewart PM. A switch in dehydrogenase to reductase activity of $11 \beta$-hydroxysteroid dehydrogenase type 1 upon differentiation of human omental adipose stromal cells. Journal of Clinical Endocrinology and Metabolism 200287 1205-1210. 
5 Murphy VE \& Clifton VL. Alterations in human placental $11 \beta$-hydroxysteroid dehydrogenase type 1 and 2 with gestational age and labour. Placenta 200324 739-744.

6 McMullen S, Osgerby JC, Thurston LM, Gadd TS, Wood PJ, Wathes DC \& Michael AE. Alterations in placental $11 \beta$-hydroxysteroid dehydrogenase (11ßHSD) activities and fetal cortisol: cortisone ratios induced by nutritional restriction prior to conception and at defined stages of gestation in ewes. Reproduction 2004127 717-725.

7 McTernan CL, Draper N, Nicholson H, Chalder SM, Driver P, Hewison M, Kilby MD \& Stewart PM. Reduced placental $117 \beta$-hydroxysteroid dehydrogenase type 2 mRNA levels in human pregnancies complicated by intrauterine growth restriction: an analysis of possible mechanisms. Journal of Clinical Endocrinology and Metabolism 200186 4979-4983.

8 Kitanaka S, Tanae A \& Hibi I. Apparent mineralocorticoid excess due to $11 \beta$-hydroxysteroid dehydrogenase deficiency: a possible cause of intrauterine growth retardation. Clinical Endocrinology $199644353-359$.

9 Kajantie E, Dunkel L, Turpeinen U, Stenman UH, Wood PJ, Nuutila M \& Andersson S. Placental 11ß-hydroxysteroid dehydrogenase-2 and fetal cortisol/cortisone shuttle in small preterm infants. Journal of Clinical Endocrinology and Metabolism $2003 \mathbf{8 8}$ 493-500.

10 Wyatt SM, Kraus FT, Roh CR, Elchalal U, Nelson DM \& Sadovsky Y. The correlation between sampling site and gene expression in the term human placenta. Placenta 200526 372-379.

11 Juez G, Lucero E, Ventura-Juncá P, Tapia J, González H \& Winter A. Estudio neonatal del crecimiento intrauterino en 11543 recién nacidos chilenos de clase media 1978-1987. Revista Chilena de Pediatria $198960198-202$.

12 Johnson MC, Vega M, Vantman D, Troncoso JL \& Devoto L. Regulatory role of angiotensin II on progesterone production by cultured human granulosa cells. Expression of angiotensin II type-2 receptor. Molecular Human Reproduction 19973 663-668.

13 Strinic T, Roje D, Marusic J \& Capkun V. Cord blood cortisol level is lower in growth-restricted newborns. Journal of Obstetrics and Gynaecology Research 200733 144-150.

14 Parker CR Jr, Buchina ES \& Barefoot TK. Abnormal adrenal steroidogenesis in growth-retarded newborn infants. Pediatric Research 199435 633-636.

15 Jones CT, Lafeber HN \& Roebuck MM. Studies on the growth of the fetal guinea pig. Changes in plasma hormone concentration during normal and abnormal growth. Journal of Developmental Physiology $19846461-472$.

16 Liggins GC. Adrenocortical-related maturational events in the fetus. American Journal of Obstetrics and Gynaecology $1976 \mathbf{1 2 6}$ 931-941.

17 Nicolaides KH, Soothill PW, Rodeck CH \& Campbell S. Ultrasoundguided sampling of umbilical cord and placental blood to assess fetal wellbeing. Lancet 19861 1065-1067.

18 Dy J, Guan H, Sampath-Kumar R, Richardson BS \& Yang K. Placental 11 $\beta$-hydroxysteroid dehydrogenase type 2 is reduced in pregnancies complicated with idiopathic intrauterine growth restriction: evidence that this is associated with an attenuated ratio of cortisone to cortisol in the umbilical artery. Placenta 2008 29 193-200.
19 Economides DL, Nicolaides KH \& Campbell S. Metabolic and endocrine findings in appropriate and small for gestational age fetuses. Journal of Perinatal Medicine 1991 19 97-105.

20 Economides DL, Nicolaides KH, Linton EA, Perry LA \& Chard T. Plasma cortisol and adrenocorticotropin in appropriate and small for gestational age fetuses. Fetal Therapy $19883158-164$.

21 Goland RS, Tropper PJ, Warren WB, Stark RI, Jozak SM \& Conwell IM. Concentrations of corticotrophin-releasing hormone in the umbilical-cord blood of pregnancies complicated by pre-eclampsia. Reproduction, Fertility, and Development 19957 1227-1230.

22 Struwe E, Berzl GM, Schild RL, Beckmann MW, Dörr HG, Rascher W \& Dötsch J. Simultaneously reduced gene expression of cortisol-activating and cortisol-inactivating enzymes in placentas of small-for-gestational-age neonates. American Journal of Obstetrics and Gynaecology $200719743 \mathrm{e} 1-43 \mathrm{e} 6$.

23 McMillen IC, Warnes KE, Adams MB, Robinson JS, Owens JE \& Coulter CL. Impact of restriction of placental and fetal growth on expression of 11 $\beta$-hydroxysteroid dehydrogenase type 1 and type 2 messenger ribonucleic acid in the liver, kidney, and adrenal of the sheep fetus. Endocrinology $2000141539-543$.

24 Li RS, Nakaqawa Y, Liu YJ, Fujisawa Y, Sai S, Nakanishi T, Chapman KE, Sekl JR \& Ohseki T. Growth hormone inhibits the $11 \beta$-hydroxysteroid dehydrogenase type 1 gene promoter activity via insulin-like growth factor I in HepG2 cells. Hormone and Metabolic Research $200840286-288$.

25 Iñiguez G, Gonzalez C, Johnson MC \& Cassorla F. Expression of IGF-I and IGF-I receptor (IGF-IR) in placentas from small for gestational age newborns. Relation with birth length. Presented in III Latin-American Symposium on maternal-fetal Interaction and placenta: basic \& clinical research. Placenta 200829 102-133.

26 Rogerson FM, Kayes KM \& White PC. Variation in placental type 2 $11 \beta$-hydroxysteroid dehydrogenase activity is not related to birth weight or placental weight. Molecular and Cellular Endocrinology 1997128 103-109.

27 Shams M, Kilby MD, Somerset DA, Howie AJ, Gupta A, Wood PJ, Afnan M \& Stewart PM. 11 $\beta$-Hydroxysteroid dehydrogenase type 2 in human pregnancy and reduced expression in intrauterine growth restriction. Human Reproduction 1998 13 799-804.

28 Beitins IZ, Bayard F, Ances IG, Kowarski A \& Migeon CJ. The metabolic clearance rate, blood production, interconversion and transplacental passage of cortisol and cortisone in pregnancy near term. Pediatric Research 19737 509-519.

29 Murphy VE, Gibson PG, Giles WB, Zakar T, Smith R, Bisits AM, Kessel CG \& Clifton VL. Maternal asthma is associated with reduced female fetal growth. American Journal of Respiratory and Critical Care Medicine $2003 \mathbf{1 6 8} 1317-1323$.

30 Pepe GJ, Davies WA, Dong KW, Luo H \& Albrecht ED. Cloning of the $11 \beta$-hydroxysteroid dehydrogenase (11 $\beta$-HSD)- 2 gene in the baboon: effects of estradiol on promoter activity of $11 \beta$-HSD-1 and -2 in placental JEG-3 cells. Biochimica et Biophysica Acta 1999 1444 101-110.

Received 8 June 2009

Accepted 14 June 2009 